\title{
Hazards of setting targets to eliminate disease: lessons from the leprosy elimination campaign
}

Diana Lockwood and colleagues reflect on the global leprosy elimination programme and challenge the wisdom of WHO's elimination strategies

\author{
Diana N J Lockwood professor of tropical medicine ${ }^{1}$, Vanaja Shetty senior researcher ${ }^{2}$, Gerson \\ Oliveira Penna medical and senior researcher ${ }^{3}$
}

${ }^{1}$ London School of Hygiene and Tropical Medicine, London WC1E 7HT, UK ; ${ }^{2}$ Foundation for Medical Research, Mumbai, India; ${ }^{3}$ Tropical Medicine Centre, University of Brasilia, Brazil

\begin{abstract}
Elimination of a disease sounds attractive, but as the recent re-emergence of polio has shown, it is difficult to accomplish. As part of its roadmap for reducing the burden of neglected tropical diseases, the World Health Organization has identified five diseases for elimination by 2015 and a further eight by 2020. ${ }^{1}$ Although setting these ambitious targets has the potential to focus money and resources, unless the targets are realistic they can have unforeseen consequences. We use the experience of the 1991 campaign to eliminate leprosy to show how targets can end up causing harm to patients.
\end{abstract}

\section{Why choose leprosy?}

Leprosy is a stigmatising and potentially disabling disease. Despite the introduction of an a global treatment programme in the 1980 s around 230000 cases are diagnosed annually, mainly in India and Brazil but also in 41 other countries. ${ }^{2}$ Leprosy is caused by Mycobacterium leprae and is spread through droplets. ${ }^{3}$ However, the disease can be treated with a six or 12 month course of multidrug therapy (rifampicin, dapsone, and clofazimine), which has a cure rate of $98 \%$. $^{4}$ The condition can be diagnosed clinically by recognising a range of characteristic skin lesions and palpating thickened peripheral nerves (box 2). Diagnosis can be confirmed through detection of acid fast bacilli in slit skin smears or through granulomatous inflammation in skin and nerve biopsy samples. ${ }^{5} \mathrm{Up}$ to $60 \%$ of patients have peripheral nerve damage at diagnosis, which requires treatment with steroids lasting several months. ${ }^{67}$ Even after effective treatment long term morbidity can be problematic; immune mediated complications can occur for years and education and monitoring are needed to prevent damage to hands, feet and eyes in those with peripheral neuropathy. ${ }^{7}$

After a WHO expert committee on leprosy recommended fixed duration antibacterial multidrug therapy for leprosy patients in $1982,{ }^{8}$ it was postulated that effective treatment would interrupt transmission globally, and in 1991 the World Health Assembly passed a resolution to "eliminate leprosy as a public health problem by the year 2000."

\section{What does elimination mean?}

The target for elimination of leprosy (and other diseases) as a public health problem did not mean achieving a prevalence or incidence of zero. For leprosy WHO set a target to achieve a prevalence of less than one case per 10000 population at a global level. ${ }^{9}$ The selection of this number was arbitrary and not supported by mathematical modelling of leprosy data. ${ }^{10}$ WHO's leprosy unit in Geneva monitored the elimination programme, with programme managers in endemic countries required to report annual leprosy figures for publication.

\section{Reality of eliminating a disease}

The leprosy elimination strategy had strengths. It committed governments, donors, and health workers to focus on leprosy ${ }^{11}$ and facilitated free drug treatment. ${ }^{12}$ Diagnosis was simplified with a straightforward field based classification based on counting the number of skin lesions ${ }^{13}$ and new case detection was promoted with innovative approaches. ${ }^{14}$ Mass detection campaigns were held to detect early cases and special progrmammes were set up to detect cases in nomadic populations.

However, India and Brazil, two countries with high prevalences of leprosy, provide case studies of how the elimination target had unintended consequences. In India from 1983 there was an energetic campaign supported by the Indian government and leprosy non-governmental organisations, which had the initial effect of increasing detection rates. Despite efforts to clean the leprosy register by removing patients who had completed antibacterial treatment, many of whom had chronic complications, India failed to meet the 2000 target and the date for elimination was moved to 2005. In order to help meet this 


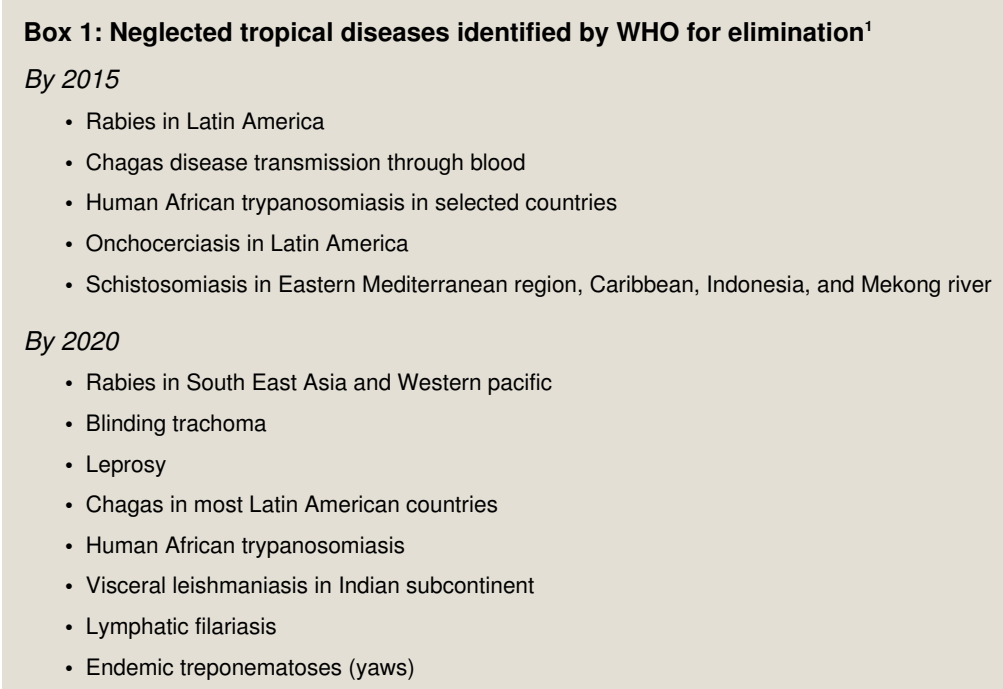

Box 2: Case definition for leprosy (WHO, 2012)

Presence of one of the following:

- Loss of sensation in pale or reddish skin lesions

- Peripheral nerves with loss of sensation or weakness of the muscles supplied by that nerve

- Acid fast bacilli in a slit skin smear sample

target the country moved to voluntary reporting and stopped actively seeking new cases and screening contacts (box 3). Detection rates fell by $75 \%$ between 2003 and 2005 (fig $1 \Downarrow$ ).

Although India met the 2005 target, many players questioned the reported leprosy figures, and independent studies showed many undiagnosed patients. Leprosy patients petitioned the Indian parliament about post-elimination services. The government commissioned a national sample survey of 15 million people in 2010, which had a case detection rate of 2.57 per 10000 . The survey findings have not yet been published nor mentioned on the website. In 2011 India reported 127509 new cases. ${ }^{18}$ The difference between the reported and observed estimates suggests that up to half of India's leprosy cases are not being reported. India has been reporting about 130000 new cases a year (fig $1 \Downarrow$ ), which keeps it safely in the eliminated leprosy category. There is therefore no incentive to find new cases.

After closing its leprosy colonies in the 1970s and integrating leprosy services into primary care, Brazil was already making progress in reducing the disease. It adopted the WHO multidrug treatment regimen in 1991 and established referral centres integrated with dermatological services. ${ }^{19}$ A successful research programme was also set up, funded by the WHO Immunology of Leprosy Project. New case detection continued at a steady rate, and this should have been congratulated (fig $2 \Downarrow$ ). ${ }^{20}$

However, the programme was under pressure to show progress towards elimination, and the 2004 returns omitted patients detected during October to December 2004 because they were not yet registered. ${ }^{19}$ This enabled Brazil to achieve elimination in 2005, but this was retracted when the missing patients were reinstated (box 4). ${ }^{18}$ The under-reporting of cases resulted in a shortage of drugs for treatment of new patients.

The country is again under pressure to reach the elimination target. Yohei Sasakawa, chairman of the Nippon Foundation, which funds the WHO elimination programme, announced that the country would reach the target at a Brazilian leprosy conference in October 2011. ${ }^{21}$ Academics in Brazil felt that they were being pressured, and this announcement was widely discussed on the web based leprosy mailing list (http:// leprosymailinglist.blogspot.co.uk/).

Globally, the leprosy elimination campaign contained an inherent problem because it was assumed that transmission would drop when case detection and treatment were widened. The possibility that this might not happen in some countries was not considered. New case detection rates in both India and Brazil showed evidence of ongoing transmission into the $21 \mathrm{st}$ century (figs $1 \Downarrow$ and $2 \Downarrow$ ). ${ }^{22}$ However, both programmes were pressed to meet the target of leprosy elimination by WHO and the Nippon Foundation. This could be done only by reporting fewer patients. The Indian programme adopted measures that ensured that fewer patients were registered, including not registering single lesion cases and no tracing of household contacts, even though this is not good public health practice. ${ }^{16}$ These changes led to patients being undiagnosed ${ }^{17}$ and experiencing important delays in starting treatment. ${ }^{23}$

\section{Damage from chasing a target}

Leprosy was an inappropriate disease to choose for elimination. The biology of leprosy means that it is not suitable for an elimination target within 10 years. The incubation period is long - 2-15 years depending on the type of leprosy ${ }^{3}$ - so new patients can continue to present for many years after successful control campaigns have ended. South Africa attained elimination rates in 1926 but new cases still present today. ${ }^{24}$ Modelling of the leprosy elimination strategy based on trends in case detection rates for 1995-8 predicts that it will slow transmission but that complete elimination will take decades to achieve. ${ }^{25}$

Obsession with the leprosy target caused schisms in the leprosy world. Leprosy non-governmental organisations were asked to leave the Global Alliance for the Elimination of Leprosy, which meant that the organisations that lead work nationally had no input to global leprosy health policy. 


\section{Box 3: India: Strategies for leprosy control and elimination as a public health problem, 1983-2012}

1983: Government establishes a national leprosy eradication programme with strategy of early detection of cases by surveys and contact examination and treatment with multidrug regimen

1996-7: Fixed duration treatment introduced with "cleaning" of registers and patients not on treatment removed from the list. New case detection rate $4.6 / 10000$

1997: Campaigns to reach undetected cases initiated

1998: Modified leprosy elimination campaigns launched emphasising public awareness and voluntary reporting of patients. One million new cases were detected in five campaigns

1999: New case detection peaked at 8.9/10 000

2000: India did not meet elimination target because the national prevalence was 5.2/10 000

Altered strategy to reach elimination target

2000: WHO proposes "final push" and moves target date to $2005^{15}$

2002: National health policy set the goal for leprosy elimination by 2005 and national detection rate began to fall $25 \%$ a year (fig $1 \downarrow$ ) 2004: Leprosy services moved into general healthcare services with large scale staff training. Voluntary reporting of patients became the main strategy

2005: WHO Kathmandu produced policy directives to reduce prevalence, which included the following ${ }^{16}$ :

- Stop all active searches for new case detection.

- New cases to be given multidrug treatment only after validation by authorities locally

- Delete names of the patients from the register as they receive the last dose of treatment

- Do not register single lesion leprosy cases

- Cease screening household contacts

2005: India achieved elimination nationally

2007: Independent surveys in Maharashtra show cases levels of 2.96-9.52/10 000 ${ }^{17}$

2009: National Forum of Leprosy Patients petitioned parliament to investigate the numbers of leprosy patients

2010: National sample survey of 15 million people examined detects 2177 cases. Weighted new cases rate estimated at 2.5/10 000 with $11.2 \%$ with visible deformities (WHO grade 2 disability). Results not yet released to public

\section{Box 4: Strategies for leprosy control and elimination as a public health problem in Brazil, 1980-2013}

1980: Leprosy clinics established in general health service clinics and health surveillance started

1991: WHO multidrug regimen adopted as treatment in national leprosy programme

2000: Stable numbers of new leprosy patients in Brazil, with small increase year on year

2005: Brazil reached elimination target, 38423 leprosy patients were registered. This was achieved by omitting the patients registered in the last quarter of 2004. The final figure was corrected to 51000 patients (June 2005). ${ }^{18}$

2006: Shortage of drugs because of under-reporting of case numbers

2007-10: Slow fall in incidence and a slight rise in prevalence, and Brazilian government made diplomatic efforts to revise the WHO leprosy elimination target.

2010: National guidelines issued for care, surveillance, and control of leprosy in primary care

2010: $90 \%$ of leprosy patients receiving treatment in primary care

2000-11: Decentralisation of leprosy control with big increase $(283 \%)$ in the number of health units treating leprosy patients

2011: Leadership of Brazilian Health Surveillance changed and elimination as a public health problem again became a target

2013: Discussions about the possibility of leprosy elimination in 2015 resumed

In 2007 WHO abandoned the elimination target for leprosy programme and instead set a target based on disability rates with the aim of improving focus on prevention of disability. ${ }^{26}$ Despite the shift in emphasis WHO still reports global leprosy rates and which countries have achieved elimination. Political commitment to leprosy has been lost. Funding and support for leprosy agencies have been declining at $5 \%$ a year for the past five years (International Federation of Anti-Leprosy Associations (ILEP), personal communication). Skills in diagnosing and managing leprosy have also been lost as programmes have been left unsupported. ${ }^{27}$ This has also been accelerated by the transfer of diagnosis and management of leprosy to peripheral health workers in many countries, away from specialist centres. The rhetoric on elimination has discouraged dermatologists from engaging with leprosy programmes, even though they may be diagnosing cases in the private sector, because they believe leprosy is eliminated. ${ }^{19}$

Academic work on leprosy has declined; it rarely figures in medical school curriculums even in endemic countries, and research has declined. ${ }^{28}{ }^{29}$ Young researchers perceive that the disease is eliminated. The International Journal of Leprosy ceased publication in 2005 with an editorial noting the absence of scientific evidence for the elimination policy. ${ }^{30}$

\section{Future of elimination}

The terminology of leprosy elimination was confused and misleading. Many people, from policy makers to observers, understood the goal to be complete elimination rather than reduced prevalence. It is important in future that those involved in campaigns, politicians, funders, health services, and the wider media are clear about what elimination means. Although WHO has defined the terms "eradication," "elimination," and "elimination as a public health problem," the possibility of confusion remains, and the terms could be misused for political purposes (box 5). ${ }^{31} 32$

Elimination of any disease is a powerful target and sets high expectations. Targets used judiciously can energise programmes, and the leprosy campaign reached out to many countries and ensured that millions of patients were detected and cured and 


\section{Box 5: WHO definitions of elimination'}

Control-Reduction of disease incidence to a locally acceptable level

Elimination-Reduction of the incidence of infection to zero

Eradication-Permanent worldwide reduction of infection to zero

gave leprosy a much higher profile. However, this achievement has been lost in the retrenching that has been required to take forward planning for a chronic disease. The lessons of leprosy show that monitoring of targets must be transparent. Workers strive to reach targets and find unexpected ways of doing so, particularly if incentives or pressure is exerted on them. This mirrors the use of targets elsewhere-for example, in the English NHS where targets can disrupt the focus of services. ${ }^{33}$

A target to eliminate should be set only if it is realistic. The following conditions are needed: straightforward diagnosis, effective treatment, low transmissibility, and ability to differentiate between current and past infection. Of the diseases listed for elimination on the WHO roadmap only rabies in Latin America fulfils these conditions.

When it was clear that leprosy transmission continued in many countries the appropriate response should have been to redefine the campaign rather than cling on to it. It is important to learn the lessons from earlier elimination programmes. ${ }^{34}$ Targets need to be evidence based. Like a battle strategy, they need to be reviewed regularly and amended when inappropriate.

We thank Doug Soutar, general secretary of ILEP (the International Federation of Anti-Leprosy Associations) and Maggie Armstrong for their help.

Contributors and sources: DNL wrote the first version of the manuscript. VS contributed the data and analysis on India. GP contributed the data and discussion on Brazil. All three authors have contributed to the subsequent versions and final version.

Competing interests: We have read and understood the BMJ policy on declaration of interests and have no relevant interests to declare.

Provenance and peer review: Not commissioned; externally peer reviewed.

WHO. Accelerating work to overcome the global impact of neglected tropical diseases-a roadmap for implementation. WHO, 2012.

2 Global leprosy situation, 2012. Wkly Epidemiol Rec 2012;87:317-28.

3 Fine PE. Leprosy: the epidemiology of a slow bacterium. Epidemiol Rev 1982;4:161-88.

4 Scollard DM, Adams LB, Gillis TP, Krahenbuhl JL, Truman RW, Williams DL. The continuing challenges of leprosy. Clin Microbiol Rev 2006;19:338-81.

5 Lockwood DNJ. In: Warrell DA CT, Firth JD, ed. Oxford textbook of medicine . 5 th ed. Oxford University Press, 2010

6 Lockwood D, Saunderson PR. Nerve damage in leprosy: a continuing challenge to scientists, clinicians and service providers. Int Health 2012;4:240-52.
7 Staples J. Interrogating leprosy stigma: why qualitative insights are vital. Lepr Rev 2011;82:91-7

8 WHO. Chemotherapy of leprosy for control programmes. WHO Tech Rep Ser 1982;675

9 World Health Assembly. Elimination of leprosy: resolution 44.9, 13 May 1991. Handbook of resolutions and decisions of the World Health Assembly and the Executive Board. 3rd ed. WHO, 1993.

10 Penna GO. Leprosy: the need to employ evidence-based medicine in control policies around the world. Lepr Rev 2011;82:210-2.

11 Ganapati R, Pai VV. Has the term "elimination" outlived its utility? Int J Lepr 2005;73:229.

12 WHO. WHO donated MDT. www.who.int/lep/mdt/donation/en/index.html.

13 WHO Expert Committee on Leprosy. WHO Tech Rep Ser 1998;874:1-43.

14 Richardus JH, Habbema JD. The impact of leprosy control on the transmission of $\mathrm{M}$. leprae: is elimination being attained? Lepr Rev 2007;78:330-7.

15 WHO. The final push strategy to eliminate leprosy as a public health problem: questions and answers. WHO, 2002.

16 WHO. National programme managers for leprosy elimination. Report of an intercountry meeting, Katmandu, Nepal, 6-8 Jan 2005. WHO South East Asia Office, 2005.

17 Shetty VP, Thakar UH, D'Souza E, Ghate SD, Arora S, Doshi RP, et al. Detection of previously undetected leprosy cases in a defined rural and urban area of Maharashtra, Western India Lepr Rev 2009;80:22-33.

18 Leprosy update, 2011. Wkly Epidemiol Rec 2011;86:389-99.

19 Talhari S, Penna G. Considerations about global policy for leprosy control. Rev Soc Bras Med Trop 2005;38:362-4

20 Penna ML, Temporao JG, Grossi MA, Penna GO. Leprosy control: knowledge shall not be neglected. J Epidemiol Community Health 2011;65:473-4.

21 Noto S. Why is Brazil doing this? 2011. www.aifo.it/english/resources/online//ml-archives/ 2011/041211.htm.

22 Lockwood DN, Suneetha S. Leprosy: too complex a disease for a simple elimination paradigm. Bull World Health Organ 2005;83:230-5.

23 Siddiqui MR, Velidi NR, Pati S, Rath N, Kanungo AK, Bhanjadeo AK, et al. Integration of leprosy elimination into primary health care in Orissa, India. PLoS One . 2009;4:e8351.

24 Durrheim DN, Fourie A, Balt E, Le Roux M, Harris BN, Matebula M, et al. Leprosy in Mpumalanga Province, South Africa-eliminated or hidden? Lepr Rev 2002;73:326-33.

25 Meima A, Smith WC, van Oortmarssen GJ, Richardus JH, Habbema JD. The future incidence of leprosy: a scenario analysis. Bull World Health Organ 2004:82:373-80.

26 WHO. Global strategy for further reducing the leprosy burden and sustaining leprosy control activities 2006-2010. WHO, 2006.

27 Liu D, Li G, Huang W, Gao J, Yue C, Xiao Q. Analysis of newly detected leprosy cases and misdiagnosis in Wuhan (1990-2004). Lepr Rev 2009;80:410-5.

28 Schoonbaert $D$, Demedts $V$. Analysis of the leprosy literature indexed in Medline (1950-2007). Lepr Rev 2008;79:387-400.

29 G-Finder. Neglected disease research and development: new times. new trends. 2009:64 www.policycures.org/downloads/G-FINDER_survey_of_global_R\&D_funding_for_ Neglected_diseases_2009.pdf.

30 Scollard DM. Leprosy research declines, but most of the basic questions remain unanswered. Int J Lepr Other Mycobact Dis 2005;73:25-7.

31 WHO. Report of the WHO Strategic and Technical Advisory Group for Neglected Tropical Diseases. 2012. www.who.int/neglected diseases/NTD STAG Report 2012.pdf.

32 Henderson DA. Eradication: lessons from the past. Bull World Health Organ 1998:76 (suppl 2):17-20.

33 Bevan GHC. Have targets improved performance in the English NHS? BM 2006;332:419-22.

34 Novartis Foundation. How to curb the incidence of leprosy? 2013. www.novartisfoundation. org.

Cite this as: BMJ 2014;348:g1136

(c) BMJ Publishing Group Ltd 2014 


\section{Figures}

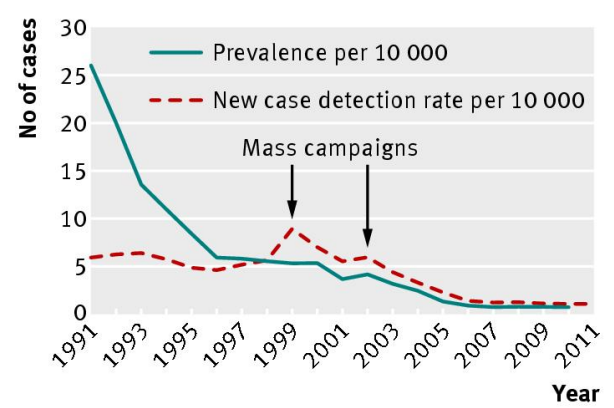

Fig 1 Incidence and prevalence of leprosy in India, 1991-2011 (data from Weekly Epidemiological Record)

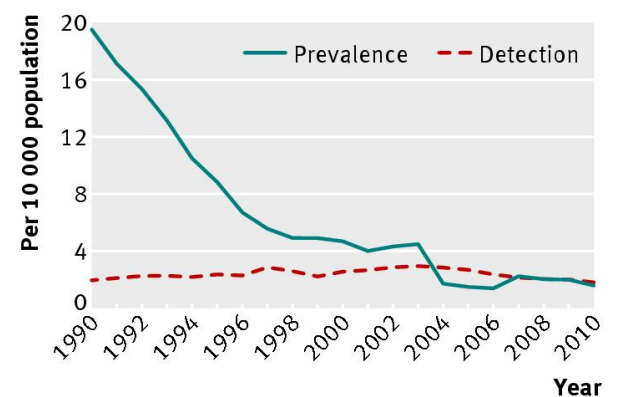

Fig 2 Leprosy prevalence and detection rates in Brazil, 1990-2010 (data from Brazilian Ministry of Health) 